\title{
Transnational collaboration for faculty development in health professions education in Mongolia
}

\author{
Hyun Bae Yoon', Jwa-Seop Shin', Seung-Hee Lee', Do-Hwan Kim', Minsun Sung ${ }^{1}$, Nomin Amgalan² and \\ Tselmuun Chinzorig ${ }^{2}$ \\ ${ }^{1}$ Department of Medical Education, Seoul National University College of Medicine, Seoul, Korea, and ${ }^{2}$ Department \\ of Education Policy and Management, Mongolian National University of Medical Sciences, Ulaanbaatar, Mongolia
}

Purpose: The Mongolian National University of Medical Sciences is the only national university in Mongolia and has produced more than $90 \%$ of health professionals in the country. Experts from Mongolia and Korea embarked on a collaborative effort to develop educational programs for faculty development based on the personal and professional needs of faculty members. This study aimed to evaluate the outcomes of those educational programs to determine whether this transnational collaboration was successful. Methods: A needs assessment survey was conducted among 325 faculty members. Based on the results of this survey, the joint expert team developed educational programs on seven core topics: clinical teaching, curriculum development, e-learning, item writing, medical research, organizational culture, and resident selection. Surveys evaluating the satisfaction and the attitudes of the participants were conducted for each program.

Results: Throughout the 17-day program, 16 experts from Korea and 14 faculty members from Mongolia participated as instructors, and a total of 309 participants attended the program. The average satisfaction score was 7.15 out of 8.0, and the attitudes of the participants towards relevant competencies significantly improved after each educational program.

Conclusion: The faculty development programs that were developed and implemented as part of this transnational collaboration between Mongolia and Korea are expected to contribute to the further improvement of health professions education in Mongolia. Future studies are needed to evaluate the long-term outcomes of these educational programs.

Key Words: Transnational collaboration, Faculty development, Health professions education

\section{Introduction}

The World Health Organization has recently emphasized a new goal for global health: universal health coverage and the establishment of competent human resources to deliver satisfactory health care services to the entire global population [1]. However, although developing countries are striving to strengthen their human resources capacity regarding health care, they are still experiencing challenges in health professions education [2]. Their efforts to expand the pool of competent health professionals are often hindered by a lack of well-trained faculty members who can provide professional training and education [3]. Therefore, appropriate and effective faculty development programs are crucial for developing countries in order to overcome these challenges [4]. Collaboration among institutions
Received: July 19, 2016 • Revised: September 8, 2016 • Accepted: October 6, 2016 Corresponding Author: Jwa-Seop Shin (http://orcid.org/0000-0002-6251-3616) Department of Medical Education, Seoul National University College of Medicine, 103 Daehak-ro, Jongno-gu, Seoul 03080, Korea

Tel: +82.2.740.8175 Fax: +82.2.741.1186 email: hismed1@snu.ac.kr
Korean J Med Educ 2016 Dec; 28(4): 381-390.

https://doi.org/10.3946/kjme.2016.43

eISSN: 2005-7288

(C) The Korean Society of Medical Education. All rights reserved. This is an open-access article distributed under the terms of the Creative Commons Attribution Non-Commercial License (http:// creativecommons.org/licenses/by-nc/3.0/), which permits unrestricted non-commercial use, distribution, and reproduction in any medium, provided the original work is properly cited. 
and countries is especially important for countries and institutions with limited resources and financial constraints [5]. In fact, collaboration is becoming prominent in diverse areas of medical education, including learning experiences, teaching activities, and faculty development [6], and the spectrum of collaboration is also broadening from the individual level to the institutional level, and even further to the transnational level [7]. Some leading examples of transnational collaboration for faculty development already exist, such as the educational programs of the Foundation for Advancement of International Medical Education and Research Institute $[8,9]$. Mongolia is a developing country in Asia that is facing rapid changes in health care and new emerging needs. The Mongolian National University of Medical Sciences (MNUMS) is the only national university for health professions education and biomedical research, was established at 1942, and has trained more than $90 \%$ of the health professionals in the country. It includes the School of Medicine, the School of Pharmacy and Biomedical Sciences, the School of Dentistry, the School of Nursing, and the School of Public Health, with approximately 800 faculty members and 10,000 undergraduate and graduate students. Although it has a long history and many faculty members, poor faculty development has been found to be a major obstacle to improvements in health professions education. With the support of the Korea International Cooperation Agency, which is the Korean governmental organization for official development assistance, experts from Mongolia and Korea were able to collaborate to plan, develop, and implement educational programs for faculty development in health professions education in Mongolia.

This study had two aims. The first was to analyze the key features of the transnational collaboration that were incorporated throughout the entire process, from the planning stage to the implementation of the educational programs. The second aim was to evaluate the outcomes of the educational programs to determine whether this transnational collaboration was successful in improving faculty development in a developing country.

\section{Subjects and methods}

\section{Planning}

At the very beginning of the planning process, all of the important stakeholders in faculty development in health professions education in MNUMS were invited to a strategic planning workshop. A total of 25 participants, including the deans of each school and branch, as well as the faculty and staff members responsible for faculty development, took part in a 3-day workshop. Medical education experts from Korea facilitated the workshop with the collaboration of Mongolian co-facilitators who were core faculty members of MNUMS. Participants (1) shared information on the current status of health professions education in Mongolia and MNUMS, (2) attempted to identify internal and external factors that can have positive or negative influences on the improvement of health professions education, (3) reached a consensus on practical visions of future health professions education in Mongolia and MNUMS, (4) analyzed underlying obstacles to those goals, (5) formulated strategic directions to overcome these obstacles and to realize their visions of future health professions education, and finally (6) planned actions to implement those strategies. Poor management system and insufficient faculty development were recognized as the major obstacles to the university, and the participants reached a consensus on the strategic directions to improve the policy, management, quality assurance, and organization culture of the university, and to strengthen the faculty development. 
A steering committee was established to manage the faculty development process, with members who were mainly drawn from the participants in the strategic planning workshop. The steering committee strongly recommended holding a larger workshop, to which many more MNUMS faculty members would be invited, in order to collect their ideas and to increase their motivation for faculty development. Based on this suggestion, an appreciative inquiry workshop was planned and implemented by the facilitators from Korea. A total of 150 faculty members participated in this 3-day workshop. Before the workshop, 96 faculty members were interviewed by the Mongolian co-facilitators and the interview results were provided to the participants. The participants were divided into 15 groups with a Mongolian co-facilitator present in each group. The workshop process followed the four steps of appreciative inquiry: discovery, dream, design, and destiny [10]. Initially, participants were asked to discover positive core elements of the stories from the interviews. The participants then shared their dreams related to the university with all the other participants. The next step was to design plans for realizing their dreams within the university. Finally, each group developed an action plan to pursue their destiny.

The results of the strategic planning workshop and the appreciative inquiry workshop were shared with the steering committee and were also reported to the executive leaders of the university. The steering committee asked the president to improve the manage system of the university and to support the faculty development program. The steering committee and the Korean experts agreed to focus on strengthening the faculty development through this project supported by Korea.

\section{Program development}

The medical education experts from Korea developed a more specific and detailed needs assessment survey form based on the results of both workshops, and this form was reviewed and revised by the steering committee. The survey was distributed to each school and 325 faculty members, comprising approximately half of the total faculty members, responded to the survey.

Based on the needs assessment results, the steering committee and the Korean medical education experts agreed to select the following seven core topics for the educational programs: clinical teaching, curriculum development, e-learning, item writing, medical research, organizational culture, and resident selection. For each topic, two to four experts from Korea and two faculty members from MNUMS were invited to develop the program. On the Korean side, a total of 16 experts from eight institutions jointly developed educational training programs for faculty development. A half-day workshop was held for the Korean experts to share the principles of developing educational programs. The first principle was to develop practical programs rather than just delivering knowledge, on the basis of adult learning theory. The second principle was to utilize the educational system of MNUMS and to try to strengthen it. The third principle was to develop sustainable educational programs so that the co-facilitators from MNUMS will be able to continue the programs themselves in the future. Continuous discussion took place between the Korean experts and the Mongolian faculty members, mainly by emails and video conference meetings, to develop the educational programs.

\section{Program evaluation}

In this study, we used the Kirkpatrick model for program evaluation [11]. For the level 1 evaluation, we conducted a survey at the end of each module to assess the satisfaction of the participants. The survey form contained free space for the participants to write their 
opinions or suggestions. We also conducted a focus group interview with nine Korean instructors after the final end of the program. For the level 2 evaluation, we conducted a survey at the beginning and the end of each module to determine whether the attitudes of the participants improved. Differences in the average score between the beginning and the end of the program were analyzed using the unpaired t-test in SPSS version 20.0 (IBM Corp., Armonk, USA). We were not able to perform level 3 and 4 evaluations in this study, as those stages of evaluation usually take place at least 3 to 6 months after the program is completed.

\section{Results}

\section{Needs assessment}

A total of 325 faculty members of MNUMS responded to the needs assessment survey (Table 1). These results showed various needs regarding faculty development in health professions education in MNUMS (Table 2). The

\section{Table 1. Characteristics of the Respondents to the Needs Assessment Survey $(n=325)$}

\begin{tabular}{lc}
\hline \multicolumn{1}{c}{ Characteristic } & Response $(\%)$ \\
\hline Gender & \\
Female & 72.3 \\
Male & 27.4 \\
Position & \\
Professor & 3.4 \\
Associate professor & 6.9 \\
Senior lecturer & 17.4 \\
Lecturer & 25.5 \\
Assistant lecturer & 24.9 \\
Staff & 0.9 \\
School & \\
Medicine & 8.9 \\
Pharmacy and Biomedical Science & 32.9 \\
Dentistry & 8.6 \\
Nursing & 10.5 \\
Public Health & 7.2 \\
\hline
\end{tabular}

Table 2. Areas of Faculty Development Prioritized by the Faculty Members $(n=325)$

\begin{tabular}{lcccc}
\hline \multicolumn{1}{c}{ Areas of faculty development } & $\begin{array}{c}\text { Very important } \\
(\%)\end{array}$ & $\begin{array}{c}\text { Somewhat } \\
\text { important }(\%)\end{array}$ & Unimportant (\%) & $\begin{array}{c}\text { Not applicable to } \\
\text { me }(\%)\end{array}$ \\
\hline Teaching skills & & & & \\
Community-based teaching & 68.2 & 28.3 & 2.9 & 0.6 \\
Clinical clerkships & 79.7 & 12.0 & 5.0 & 3.3 \\
Creating an objective structured clinical exam & 82.0 & 15.8 & 1.9 & 0.3 \\
Designing a course or educational program & 83.3 & 14.8 & 0.9 & 0.9 \\
Effective teaching strategiesfor student-centered learning & 82.0 & 15.8 & 1.9 & 0.3 \\
Evaluating a course or program & 80.9 & 17.2 & 1.5 & 0.3 \\
Evaluating learning & 81.9 & 15.9 & 1.9 & 0.3 \\
Giving effective feedback & 79.1 & 19.3 & 0.9 & 0.6 \\
Interprofessional education & 68.8 & 29.3 & 1.6 & 0.3 \\
Large group teaching & 31.7 & 50.9 & 15.5 & 1.9 \\
One-to-one teaching & 17.9 & 49.7 & 27.0 & 5.3 \\
Problem-based learning & 75.2 & 21.6 & 2.8 & 0.3 \\
Portfolios for learning & 64.1 & 28.5 & 5.9 & 1.5 \\
Small-group teaching & 71.3 & 25.3 & 2.8 & 0.6 \\
Teaching in the ambulatory setting & 62.0 & 26.3 & 7.8 & 3.9 \\
\hline
\end{tabular}




\begin{tabular}{lcccc}
\hline \multicolumn{1}{c}{ Areas of faculty development } & $\begin{array}{c}\text { Very important } \\
(\%)\end{array}$ & $\begin{array}{c}\text { Somewhat } \\
\text { important }(\%)\end{array}$ & $\begin{array}{c}\text { Unimportant }(\%) \\
\text { Not applicable to } \\
\text { me }(\%)\end{array}$ \\
\hline Teaching clinical reasoning skills & 83.3 & 12.1 & 1.9 & 2.7 \\
Teaching communication skills & 89.5 & 10.2 & 0.4 & 0 \\
Teaching evidence-based medicine & 86.8 & 9.9 & 1.5 & 1.8 \\
Teaching international medical graduates & 24.8 & 40.9 & 26.8 & 7.5 \\
Teaching others how to teach & 54.4 & 35.8 & 9.1 & 0.7 \\
Teaching procedural skills & 83.9 & 11.4 & 3.3 & 1.5 \\
Teaching professionalism & 76.1 & 19.0 & 4.5 & 0.4 \\
Teaching the "problem" student/resident & 83.9 & 14.7 & 1.1 & 0.4 \\
Scholarship & & & & \\
Writing articles and abstracts for journals & 73.2 & 24.9 & 1.6 & 0.3 \\
Critiquing research articles & 44.2 & 45.2 & 9.9 & 0.6 \\
Writing ethics proposals & 42.9 & 42.9 & 12.5 & 1.6 \\
Grant writing & 73.7 & 21.5 & 4.4 & 0.3 \\
Engaging in scholarly activities & 58.3 & 33.7 & 7.4 & 0.6 \\
Understanding scholarship on teaching & 59.0 & 35.2 & 5.2 & 0.7 \\
Presenting work at conferences & 71.4 & 24.1 & 3.8 & 0.6 \\
\hline
\end{tabular}

Table 3. Preferred Formats of Faculty Development Indicated by the Faculty Members $(n=325)$

\begin{tabular}{lccccc}
\hline \multicolumn{1}{c}{ Format } & $\begin{array}{c}\text { Most } \\
\text { preferred }(\%)\end{array}$ & $\begin{array}{c}\text { Somewhat } \\
\text { preferred }(\%)\end{array}$ & Neutral $(\%)$ & $\begin{array}{c}\text { Not preferred } \\
(\%)\end{array}$ & $\begin{array}{c}\text { Least } \\
\text { preferred }(\%)\end{array}$ \\
\hline Online course & 32.8 & 26.8 & 31.9 & 5.0 & 3.5 \\
Videoconference & 23.7 & 29.1 & 38.6 & 5.1 & 3.5 \\
Individual or group consultation & 23.7 & 27.5 & 35.1 & 6.4 & 8.9 \\
1-Hour session & 19.4 & 31.5 & 34.7 & 7.0 & 7.3 \\
Half-day workshop & 26.8 & 26.2 & 33.5 & 9.9 & 3.5 \\
Full-day workshop & 24.3 & 26.2 & 27.8 & 11.0 & 10.7 \\
A series of four to five workshops on related topics & 44.4 & 22.5 & 21.0 & 7.9 & 4.1 \\
A half day a week for 1 academic year & 20.2 & 17.9 & 26.3 & 18.3 & 17.3 \\
A half day a week for 2 academic years & 13.9 & 15.8 & 29.0 & 18.1 & 23.2 \\
\hline
\end{tabular}

Table 4. Educational Programs for Faculty Development at the Mongolian National University for Medical Sciences

\begin{tabular}{llcc}
\hline \multicolumn{1}{c}{ Topic } & \multicolumn{1}{c}{ Subtopic } & Participant & Duration \\
\hline Clinical teaching & Clinical clerkships and clinical skills training & 40 & $8 \mathrm{hr}$ (1 day) \\
Curriculum development & Outcome-based curriculum development and evaluation & 40 & $28 \mathrm{hr}$ (3.5 day) \\
E-learning & E-learning, telemedicine, and simulations & 40 & $12 \mathrm{hr}$ (1.5 day) \\
Item writing & Good item writing & 44 & $12 \mathrm{hr}$ (1.5 day) \\
Medical research & Research methodology, article writing, and translational research & 80 & $20 \mathrm{hr}$ (2.5 day) \\
Organization culture change & Appreciative inquiry facilitator training & 23 & $32 \mathrm{hr}$ (4 day) \\
Resident selection & Competency modeling and selection strategy & 42 & $24 \mathrm{hr}$ (3 day) \\
\hline
\end{tabular}

respondents preferred a series of workshops on relevant

programs (Table 3).

topics over other formats of faculty development 


\section{Implementation}

The educational programs were held consecutively for a total of 17 days over 3 weeks. Throughout the entire program, 16 experts from Korea and 14 experts from Mongolia participated as instructors, and a total of 309 participants attended the program (Table 4).

\section{Level 1: satisfaction}

The overall average satisfaction score from the participants was 7.15 out of 8.0 (Table 5). The participants were satisfied with the instructors, content, and the materials that were provided, and they felt that the programs were quite timely and helpful. The instructors

Table 5. Participants' Satisfaction with the Educational Programs (8-Point Scale)

\begin{tabular}{lcccccccc}
\hline Characteristic & $\begin{array}{c}\text { Clinical } \\
\text { teaching }\end{array}$ & $\begin{array}{c}\text { Curriculum } \\
\text { development }\end{array}$ & E-learning & $\begin{array}{c}\text { Item } \\
\text { writing }\end{array}$ & $\begin{array}{c}\text { Medical } \\
\text { research }\end{array}$ & $\begin{array}{c}\text { Organization } \\
\text { culture }\end{array}$ & $\begin{array}{c}\text { Resident } \\
\text { selection }\end{array}$ & Average \\
\hline Relevance & 6.97 & 6.93 & 7.34 & 7.30 & 7.35 & 7.08 & 6.38 & 7.05 \\
Content & 7.31 & 6.83 & 7.26 & 7.43 & 7.46 & 7.38 & 6.59 & 7.18 \\
Methods & 7.15 & 6.67 & 7.34 & 7.27 & 7.31 & 7.00 & 6.72 & 7.07 \\
Instructors & 7.22 & 6.90 & 7.37 & 7.20 & 7.37 & 7.15 & 6.90 & 7.16 \\
Materials & 7.34 & 7.10 & 7.29 & 7.50 & 7.28 & 7.23 & 6.95 & 7.24 \\
Schedule & 7.25 & 6.57 & 7.11 & 7.30 & 7.04 & 7.00 & 6.39 & 6.95 \\
Facilities & 7.38 & 7.13 & 7.21 & 7.47 & 7.01 & 6.92 & 6.79 & 7.13 \\
Achievement & 7.44 & 7.13 & 7.17 & 7.43 & 7.30 & 7.08 & 6.62 & 7.17 \\
Helpfulness & 7.34 & 7.33 & 7.54 & 7.57 & 7.57 & 7.08 & 6.67 & 7.30 \\
Average & 7.28 & 6.97 & 7.30 & 7.41 & 7.30 & 7.12 & 6.69 & 7.15 \\
\hline
\end{tabular}

Table 6. Changes in the Attitudes and Perspectives of the Participants after the Educational Programs (8-Point Scale)

\begin{tabular}{clccc}
\hline Module & \multicolumn{1}{c}{ Attitude and perspectives of the participants } & $\begin{array}{c}\text { Before the } \\
\text { program }\end{array}$ & $\begin{array}{c}\text { After the } \\
\text { program }\end{array}$ & p-value \\
\hline Clinical teaching & Commitment to clinical teaching & 5.47 & 7.13 & $<0.001$ \\
& Understanding of clinical clerkships & 5.25 & 7.25 & $<0.001$ \\
& Self-confidence in bedside teaching & 4.90 & 7.10 & $<0.001$ \\
& Self-confidence in teaching in ambulatory settings & 5.44 & 7.34 & $<0.001$ \\
& Self-confidence in assessing students in clinical clerkships & 5.31 & 7.44 & $<0.001$ \\
& Average & 5.17 & 7.21 & $<0.001$ \\
Curriculum & Understanding the steps of curriculum development & 4.14 & 6.88 & $<0.001$ \\
development & Perspectives on student-centered education & 4.90 & 6.88 & $<0.001$ \\
& Self-confidence in writing the goals and objectives & 4.90 & 6.72 & $<0.001$ \\
& Understanding of outcome-based curriculum & 4.82 & 6.78 & $<0.001$ \\
& Self-confidence in planning program evaluations & 4.66 & 6.66 & $<0.001$ \\
& Average & 4.68 & 6.78 & $<0.001$ \\
& Self-confidence in knowledge of e-learning & 3.56 & 6.48 & $<0.001$ \\
& Educational perspectives of e-learning & 5.46 & 7.18 & $<0.001$ \\
& Interest in developing e-learning programs & 5.83 & 7.20 & $<0.001$ \\
& Self-confidence in developing e-learning programs & 5.02 & 6.97 & $<0.001$ \\
& Advocacy for e-learning programs & 5.47 & 6.37 & $<0.001$ \\
& Average & 5.07 & 6.84 & $<0.001$ \\
\hline
\end{tabular}


Table 6. (Continued)

\begin{tabular}{clccr}
\hline Module & \multicolumn{1}{c}{ Attitude and perspectives of the participants } & $\begin{array}{c}\text { Before the } \\
\text { program }\end{array}$ & $\begin{array}{c}\text { After the } \\
\text { program }\end{array}$ & p-value \\
\hline Item writing & Willingness to write high-quality items & 6.08 & 7.19 & 0.002 \\
& Understanding the principles of item development & 5.92 & 7.34 & 0.003 \\
& Self-confidence in developing various types of items & 6.23 & 7.28 & $<0.001$ \\
& Self-confidence in editing previous items & 6.12 & 7.34 & $<0.001$ \\
& Self-confidence in analyzing the items & 5.88 & 7.34 & $<0.001$ \\
& Average & 6.06 & 7.30 & $<0.001$ \\
Medical research & Commitment to medical research & 6.37 & 7.30 & $<0.001$ \\
& Understanding of clinical trials & 5.08 & 6.82 & $<0.001$ \\
& Willingness to join international research & 6.55 & 7.01 & 0.008 \\
& Self-confidence in writing scientific articles & 5.72 & 7.01 & $<0.001$ \\
& Understanding of publication ethics & 6.12 & 7.36 & $<0.001$ \\
& Average & 5.97 & 7.10 & $<0.001$ \\
Organizational & Importance of organizational culture & 7.82 & 7.71 & 0.594 \\
& Interest in organizational culture changes & 6.76 & 7.43 & 0.037 \\
& Understanding the methods for organizational culture changes & 5.34 & 6.20 & 0.031 \\
& Commitment to organizational culture changes & 7.29 & 7.44 & 0.661 \\
& Willingness for organizational culture changes & 7.11 & 7.30 & 0.507 \\
& Average & 6.87 & 7.44 & 0.044 \\
\hline
\end{tabular}

were also satisfied with the enthusiastic learning attitude and commitment of participants, and they expected rapid progress of the faculties and the university itself. Language barrier was found to be the main obstacle of the program. The instructors recommended that the participants should be more targeted and the topics should be more specific for effective faculty development, and to overcome the language barrier and to sustain the faculty development program, the Mongolian faculties should be trained as trainers for faculty development.

\section{Level 2: attitude}

The attitudes and the perspectives of the participants regarding the topics covered by these programs significantly improved after each educational program (Table 6). We were not able to conduct a survey for the resident selection module due to the time constraints of the program.

\section{Discussion}

This faculty development project aiming to improve health professions education in Mongolia was planned and implemented through the collaboration of experts from Korea and Mongolia. At the beginning of the project, all important stakeholders in faculty development at MNUMS were invited to a strategic planning workshop. Participatory strategic planning is wellknown as an effective way to reinforce and maintain the commitment of the participants, especially in development projects in developing countries [12]. After the strategic planning workshop, based on the consensus of the Korean experts and the steering committee, an appreciative inquiry workshop was conducted to collect the ideas of the MNUMS faculty members and to increase their motivation for faculty development. These early steps of transnational collaboration with the goal of encouraging MNUMS faculty members to engage with 
the project seemed to contribute later to the active participation of the faculty members in the educational programs. This conclusion is also supported by studies in the relevant literature that have emphasized the importance of faculty development in fostering changes in the institutional culture such that teaching scholarship is recognized and rewarded [13,14].

Based on the results of both workshops, a more specific and detailed needs assessment survey was conducted among almost half of the total faculty members. Assessing the needs of the targeted population and the community is the initial step in the process of program development and plays a crucial role in the overall success of the process [15]. The steering committee and the Korean medical education experts agreed to select seven core topics for the educational programs based on the needs assessment survey results. In this process, the personal and professional needs of the faculty members and the institutional needs of MNUMS itself were both considered, as has been strongly recommended in the recent literature on faculty development $[16,17]$. At the beginning of the program development process, a workshop was held for the Korean experts to share the principles of developing these programs. Moreover, during the development process, continuous discussion took place between the Korean experts and Mongolian faculty members, and the steering committee also provided guidance and feedback to the development team. This continuous transnational collaboration eventually led to the successful development of educational programs to meet the needs of the faculty members and the institutional needs of MNUMS.

According to the evaluations, the participants were quite satisfied with the instructors, content, and materials that were provided, and they felt the programs were very timely and helpful. Although high satisfaction itself does not guarantee learning, it is more likely that satisfied participants will continue to participate in faculty development programs in the future [18]. However, some participants suggested that the programs should be more practical and contextualized to their real-world situations, and that the schedule should have been more flexible and convenient for participation. Thus, the importance of considering the local context and institutional factors and providing institutional support for faculty development should be emphasized [19].

The attitudes and perspectives of the participants significantly improved after the educational programs. Their understanding of and perspectives on the topics that were covered, self-confidence in knowledge and skills, and commitment and willingness for teaching and research improved considerably. Since it is well known that faculty members' attitudes and misconceptions are major barriers to faculty development [20], these significant attitude changes could be a promising starting point. The only small exception was the topic of organizational culture, for which the participants already exhibited commitment and willingness for culture change even before they participated in the program.

Language barrier was found to be the main obstacle of the program. Even though there were translators for each module who translated English to Mongolian whenever it was needed, the specificity of the contents made it difficult for effective translation. The instructors recommended that we should train the Mongolian faculties as trainers for faculty development to overcome the language barrier and also to sustain the faculty development program. The instructors mentioned that they could not more specify the topic because of the diversity of the participants. For effective faculty development, the topics should be more specific and relevant according to the targeted participants.

This study aimed to analyze the key features of this transnational collaboration and to evaluate the outcomes 
of the educational programs to determine whether this collaborative effort was successful. Full engagement and active participation of the Mongolian faculty members were noted from the planning stage to the implementation of the programs. Additionally, during the development process, continuous discussion and collaboration took place between the experts from both countries. The participants were quite satisfied with the educational programs, and significant attitude changes among the participants occurred after each program. The faculty development programs that were developed and implemented as part of this transnational collaboration between Mongolia and Korea are expected to contribute to the improvement of health professions education in Mongolia. Further studies are needed to evaluate the long-time outcomes of these educational programs.

ORCID: Hyun Bae Yoon: http://orcid.org/0000-0003-4367-5350; Jwa-Seop Shin: http://orcid.org/http://orcid.org/0000-0002-6251-3616; Seung-Hee Lee: http://orcid.org/0000-0001-8672-5253;

Do-Hwan Kim: http://orcid.org/0000-0003-4137-7130

Acknowledgements: The Institutional Review Board of Seoul National University College of Medicine and Seoul National University Hospital exempted this study from review since it was an analysis of de-identified data (E-1605-007-758). The authors would like to thank the Korea International Cooperation Agency, the Mongolian National University of Medical Sciences, and especially all the experts and participants who contributed to the success of this faculty development project.

Funding: This study was supported by the Education and Research Encouragement Fund of Seoul National University Hospital.

Conflicts of interest: None.

\section{References}

1. Campbell J, Buchan J, Cometto G, David B, Dussault G, Fogstad H, Fronteira I, Lozano R, Nyonator F, PablosMéndez A, Quain EE, Starrs A, Tangcharoensathien V. Human resources for health and universal health coverage: fostering equity and effective coverage. Bull World Health Organ 2013; 91: 853-863.

2. Alkan ML. The global medical school, 2020. Med Teach 2000; 22: 527-530.

3. Mahat A, Bezruchka SA, Gonzales V, Connell FA. Assessment of graduate public health education in Nepal and perceived needs of faculty and students. Hum Resour Health 2013; 11: 16.

4. Kim DH, Yoon HB, Sung M, Yoo DM, Hwang J, Kim EJ, Lee S, Shin JS. Evaluation of an international faculty development program for developing countries in Asia: the Seoul Intensive Course for Medical Educators. BMC Med Educ 2015; 15: 224.

5. Steinert Y. Faculty development in the new millennium: key challenges and future directions. Med Teach 2000; 22: 44-50.

6. Gwee MC, Samarasekera DD, Chong YS. APMEC 2014. Optimising collaboration in medical education: building bridges connecting minds. Med Educ 2013; 47: iii-iv.

7. Harden RM. International medical education and future directions: a global perspective. Acad Med 2006; 81(12 Suppl): S22-S29.

8. Burdick W, Amaral E, Campos H, Norcini J. A model for linkage between health professions education and health: FAIMER international faculty development initiatives. Med Teach 2011; 33: 632-637.

9. Burdick WP, Diserens D, Friedman SR, Morahan PS, Kalishman S, Eklund MA, Mennin S, Norcini JJ. Measuring the effects of an international health professions faculty development fellowship: the FAIMER 
Institute. Med Teach 2010; 32: 414-421.

10. Cooperrider DL, Whitney D. Appreciative inquiry: a positive revolution in change. San Francisco, USA: Berrett-Koehler Publishers; 2005. p 1-21.

11. Kirkpatrick DL. Evaluating training programs: the four levels. 2nd ed. San Francisco, USA: Berrett-Koehler Publishers; 1998. p 19-47.

12. Gedikli B. The role of leadership in the success of participatory planning processes experience from Turkey. Eur Urban Reg Stud 2009; 16: 115-130.

13. Bland CJ, Starnaman S, Wersal L, Moorehead-Rosenberg L, Zonia S, Henry R. Curricular change in medical schools: how to succeed. Acad Med 2000; 75: 575-594.

14. Gale R, Grant J. AMEE medical education guide no. 10. Managing change in a medical context: guidelines for action. Med Teach 1997; 19: 239-249.

15. Kern DE, Thomas PA, Hughes MT. Curriculum development for medical education: a six-step approach. 2nd ed. Baltimore, USA: The Johns Hopkins University Press;
2009. p 4-98.

16. Hill F, Stephens C. Negotiating strategic direction for education staff development: the Southampton experience. Med Teach 2004; 26: 645-649.

17. McLean M, Cilliers F, Van Wyk JM. Faculty development: yesterday, today and tomorrow. Med Teach 2008; 30: 555-584.

18. Steinert $\mathrm{Y}$, Macdonald ME, Boillat M, Elizov M, Meterissian S, Razack S, Ouellet MN, McLeod PJ. Faculty development: if you build it, they will come. Med Educ 2010; 44: 900-907.

19. Wong JG, Agisheva K. Developing teaching skills for medical educators in Russia: a cross-cultural faculty development project. Med Educ 2007; 41: 318-324.

20. Skeff KM, Stratos GA, Mygdal W, DeWitt TA, Manfred L, Quirk M, Roberts K, Greenberg L, Bland CJ. Faculty development: a resource for clinical teachers. J Gen Intern Med 1997; 12 Suppl 2: S56-S63. 